\title{
The Prayer Companion
}

\section{Openness and Specificity, Materiality and Spirituality}

\author{
William Gaver ${ }^{1}$ Mark Blythe $^{2}$ Andy Boucher ${ }^{1}$ Nadine Jarvis $^{1}$ John Bowers ${ }^{1}$ Peter Wright $^{3}$ \\ ${ }^{1}$ Interaction Research Studio \\ Goldsmiths, U. of London \\ London SE14 6NW, UK \\ initial.surname@gold.ac.uk \\ ${ }^{2}$ Computer Science \\ University of York \\ York, YO10 5DD, UK \\ mblythe@cs.york.ac.uk \\ ${ }^{3}$ Department of Design \\ Sheffield Hallam University \\ Sheffield, SI 1WB, UK \\ p.c.wright@shu.ac.uk
}

\begin{abstract}
In this paper we describe the Prayer Companion, a device we developed as a resource for the spiritual activity of a group of cloistered nuns. The device displays a stream of information sourced from RSS news feeds and social networking sites to suggest possible topics for prayers. The nuns have engaged with the device enthusiastically over the first ten months of an ongoing deployment, and, notwithstanding some initial irritation with the balance of content, report that it plays a significant and continuing role in their prayer life. We discuss how we balanced specificity in the design with a degree of openness for interpretation to create a resource that the nuns could both understand and appropriate, describe the importance of materiality to the device's successful adoption, consider its implications as a design for older people, and reflect on the example it provides of how computation may serve spirituality.
\end{abstract}

\section{Author Keywords}

Interaction design, research through design, interpretability, materiality, older people, spirituality

\section{ACM Classification Keywords}

H5.m. Information interfaces and presentation (e.g., HCI): Miscellaneous.

\section{General Terms \\ Design}

\section{INTRODUCTION}

The Prayer Companion is a small device designed to serve as a resource to the prayer activity of group of cloistered nuns living in a convent in a northern English city. A text display set in a raised enclosure presents a stream of headlines from online RSS news feeds interleaved with excerpts of text drawn from social networking websites (see Figure 1). This information is updated frequently, so the result is an ongoing reminder of contemporary events

Permission to make digital or hard copies of all or part of this work for personal or classroom use is granted without fee provided that copies are not made or distributed for profit or commercial advantage and that copies bear this notice and the full citation on the first page. To copy otherwise, or republish, to post on servers or to redistribute to lists, requires prior specific permission and/or a fee.

CHI 2010, April 10-15, 2010, Atlanta, Georgia, USA.

Copyright 2010 ACM 978-1-60558-929-9/10/04 ...\$10.00. and concerns potentially relevant to the nuns' prayers. As we will describe, the nuns have engaged with the Prayer Companion enthusiastically over the ten months they have lived with it, reporting that it has played a prominent role in their prayer life, and thus we present the device as a successful example of design.

Beyond a simple case study, the Prayer Companion is an example of research through design $[3,5,15,24]$, in which design practice is brought to bear on situations chosen for their topical and theoretical potential, the resulting designs are seen as embodying designers' judgments about valid ways to address the possibilities and problems implicit in such situations, and reflection on these results allow a range of topical, procedural, pragmatic and conceptual insights to be articulated. As with many such projects, the Prayer Companion can be considered from a diverse set of perspectives, reflecting the complexity of its real-world design setting. In this paper, we focus our discussion on four themes: the balance between openness and specificity in design, the importance of the system's materiality, designing for older people, and the potential for computation to serve spirituality relatively directly.

\section{Openness and Specificity}

There is a kind of disciplinary hubris in the assumption that HCI can define systems that reflect comprehensive understandings of users, whether in terms of tasks, problems or communities of use. Such a stance casts HCI practitioners as the powerful champions of feeble users [2], but our understandings are liable to be imperfect,

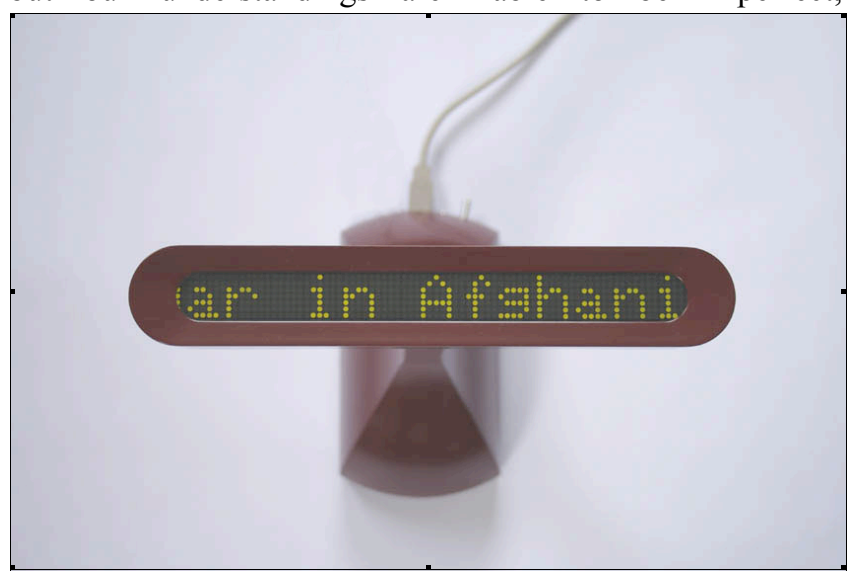

Figure 1: The Prayer Companion 
provisional and incomplete. Thus overly defined systems may be unable to encompass the many and nuanced ways people organise and give meaning to their activities, they may misrepresent exploratory and curiosity-driven activities, and may commodify personal experience, encouraging people to consume activities and meanings defined by others and alienating them from their own meaning-making.

Recently a number of researchers have explored alternative strategies in the form of systems designed to be open to multiple interpretations [7,16,11]. Several advantages are suggested for such an approach. For example, open-ended systems may fit multiple localities, as different people can understand and use them in ways that make sense for their particular situations [16]. They may encourage curiosity and exploration as users engage in making meaning with and through them [4]. Finally, they allow designers to raise topics for consideration without imposing their views [7].

Emphasising openness can be somewhat misleading, however, since designing for interpretability seldom implies the creation of 'blank canvases' [16], free of any hint about where and how they could be used. Most systems that have been described as 'open' are also constrained and situated to various degrees. They address particular topics such as domestic activities [14], the local 'vibe' [16], or nearby air travel [8], permit particular styles of interaction such as drifting, reading and watching, and disallow others such as zooming, skipping, searching or inspecting. These constraints are important in making systems that are 'about' something, suggesting initial possibilities for interaction, and avoiding clichéd forms of engagement with topics and devices. Researching potential user communities is often crucial in this process, to identify what topics might be relevant, what constraints might best encourage new perspectives on those topics, and to ensure that designs are functionally, socially and aesthetically meaningful to those communities. In short, systems are often 'open' within a constrained space of possibility.

The design of the Prayer Companion depended heavily on our understanding of the particular community for which it was designed. This was balanced, however, by a design that leaves ample room for its users' own interpretations and appropriations. In describing the device and its use, then, we hope to demonstrate and describe how successful designs may balance constraint and situatedness with openness for interpretation. One of the advantages of this balance is that such designs can occasion dialogues in which designers' and users' interpretations can develop without calling the viability of the system into question.

\section{Materiality and Aesthetics}

A deep separation between abstract functionality and material instantiation is assumed within much traditional Computer Science, but materiality can have strong effects on how computational artefacts are understood and used. Although a concern for the utilitarian impacts of form and interaction style on utility and usability are at the heart of
HCI, other aspects of materiality tend to be overlooked. For instance, the aesthetics of form and interaction may be considered both in terms of hedonic value and as cultural signifiers [10], but such considerations typically play a small role either in the description of technological visions or in the development and report of new prototypes.

In our previous work, we have developed prototype computational devices that are highly finished as material and interactive artefacts. Formal and aesthetic issues have been at the core of our development process, but their importance has usually been glossed in terms of their role in encouraging volunteers to view the devices as potential products and - to a lesser degree - in allowing us to exhibit the prototypes. Here we suggest that the Prayer Companion's materiality has been pivotal to its appropriation by the nuns, and thus highlight this as a worthy subject for empirical research and reflection.

\section{Designing for Older People}

The opportunity to develop the Prayer Companion came about through our involvement with a project on technologies for older people, one of many made possible by funding initiatives aimed at addressing the aging populations of Europe. Research on technologies for older people often associates aging with disability and the need for care, and thus focuses on topics such as augmenting memory or the social resources required for older people to remain in their own homes [12,18]. Increasingly such endeavours tend to be complemented by a recognition of the benefits of intergenerational engagement and the possibility that age-related deficits can be 'forcing functions' that produce good designs for all users $[1,15,17]$.

What these approaches and the initiatives that fund them share is the identification of 'older people' as a category of people who, by implication, share some common set of abilities, orientations and requirements. Considering our work with the nuns (most of whom are in their 80s) as an example of 'designing for older people' clearly problematises this assumption.

\section{Computation and Spirituality}

The most salient unifying feature of our user community was not their age but their commitment to a spiritual life. Over the last several years, there has been an increasing body of literature in HCI exploring the role computational technologies might play in religious and spiritual activities. For instance, Wyche et al. [23] describe how computational devices are used to support communication and coordination amongst the thousands of members of US 'mega-churches'. Woodruff and her colleagues [20] report how Orthodox Jews use home automation systems to moderate constraints imposed by the Sabbath. Wyche and Grinter [21] investigated believer's attitudes towards religious possessions, suggesting that the strong attachment these evoke may be a model for sustainable design. Finally Wyche [22] developed a cellphone application to support Muslims in keeping track of prayer times. 
Such research is valuable in addressing a basic aspect of human experience and in encouraging HCI to reconsider its own boundaries. Nonetheless, apart from [22], few if any of these studies seem to engage intimately with the specific features of spiritual activity such as the experience of prayer. Instead, religious practices are treated as social endeavours, as an aspect of identity and aspiration, as presenting pragmatic constraints to be overcome, or as communication tasks requiring support. Thus user studies and design proposals often seem to address general issues of coordinating large organizations, ameliorating constraints, building emotional relationships with products, and creating visual brand identities, rather than exploring the intimate and personal nature of religious experience. One of the motivations for engaging with the nuns in this project was to explore whether we could address their spiritual experiences more directly in our design work.

\section{THE PRAYER COMPANION}

Before discussing these themes further, we describe the process of designing and testing the Prayer Companion. We start with a portrayal of the Poor Clares sisters, both as representatives of a larger religious community and as a group with a particular history and social makeup. Following this, we describe the development of the Prayer Companion in terms of its concept, technical implementation, form and aesthetics. We then report our deployment of the device and the nuns' accounts of their experiences with it. Finally we conclude with our reflections about how this experience informs our understanding of the issues outlined above.

\section{St Johns Convent of Poor Clares Colletines}

Our introduction to the nuns was serendipitous, the result of our local team member's garden sharing a wall with the St Johns Convent of Poor Clares. Upon meeting a brother of one of the sisters and finding out that most of the Poor Clares were in their $80 \mathrm{~s}$, he asked for an introduction and invited them to participate in our project. They accepted his invitation, and we set out to learn more about them.

Because Poor Clares is an enclosed order, an in-depth observational study was clearly never going to be possible. However, the 'Extern' sister, Sister Peter, is not fully enclosed and her role involves being the main point of contact between the other sisters and the outside world. A highly articulate person, she acted as a key informant (Willis 2002) for the study, and her in-depth and patient explanations of the sisters' life of prayer were particularly important in its development. The Mother Abbess and the Mother Vicaress were also extremely generous with their time and took part in a series of interviews over a two year period. They conducted tours around the house and grounds and took part in group discussions with other sisters. Visits were made over an eighteen month period for biographical interviews and also discussions about the development of a website for their monastery. This included tours of other Christian and prayer intercession websites.
The Poor Clares are an order of Roman Catholic nuns founded in 1212 by St. Clare of Assisi and St. Francis of Assisi. Like the Franciscan Friars, the Poor Clares take vows of poverty, chastity and obedience. They also take a vow of enclosure, devoting their lives to prayer and manual labour. St. Johns Convent was founded in 1865, and though located in the centre of a northern English city it has more than six acres of grounds. Since it was set up the number of sisters has varied, reaching as many as forty in the 1950 s. When this study began there were fourteen sisters, the majority of whom were in their eighties. There are now eleven. Numbers have been dwindling for decades and the current cohort is itself the result of a merger with another convent some 20 years ago, traces of which remain in the ways the nuns are characterized by themselves and each other. The convent is a strict hierarchical organization but it is also democratic. The nuns' vow of obedience is ultimately to God but promises are also made to the Mother Abbess. The role of Mother Abbess is an elected one along with other positions of authority including Mother Vicaress and Counsellor. Apart from Sister Peter, the nuns only leave the convent when required e.g. to visit the doctor. They greet guests from behind a counter in a separate anteroom, and can visit with family and close friends in a lounge area just outside enclosure.

Since the monastery was established the life of the nuns has followed the same routine. They rise at 5:30 unless it is a feast day or a holiday when they sleep in till 6:00. They say the Divine Office (psalm or scripture readings) five times a day and celebrate mass at noon. Their work includes packaging Eucharist wafers for distribution around the country as well as maintaining the monastery and gardens in which they grow their own food (a retired gardener comes in five days a week to help). Other time is set aside for personal prayer, though as Sister Peter explained "I can be sweeping a floor and be utterly in God's presence.". At $7: 45$ in the evening they have 'recreation' when they talk to one another. This is the time of day to relax and their talk is often very funny "Sometimes it's just absolute rubbish" (Sister Peter). They go to bed at 9, or 10 if they have chores still to do. Their food is simple and vegetarian. They take tea or coffee at breakfast but only boiled water with lunch.

Prayer is central to their lives and runs beneath all of their activities. The nuns view their prayer as having practical value to the world although the world may not be aware of it or believe it:

\footnotetext{
"We're not teaching, we're not nursing, we're not doing social work, we're not bringing up families, we're not working in factories, we're not doing any of those things. So our role has to be that we are standing in the presence of God all the time, and in doing that it has to bring [..] benefit to humanity. And, as I say, so many people do contact us to ask for prayer." (Sister Peter).
}

The nuns are removed from the world and yet their prayer must be "pertinent". Although they are enclosed from the 
rest of the world they do not ignore it: "for us having news is not keeping in touch with what's going on, it's to keep the prayer pertinent to what's going on... I mean if there's an earthquake in Indonesia well... if we're still praying for the situation in Northern Ireland" (Sister Peter). For this reason the nuns had long listened to news broadcasts on the radio. They also got news from Catholic news agencies, the diocese and, following the purchase of a computer two weeks before this study began, internet and email.

Despite what may sound like a severe existence, we found the monastery to be beautiful, serene and spacious (though freezing in the winter), and the nuns to be lively, happy and full of humour. "We are simple people", the Mother Abbess explained. Sister Peter elaborates:

"People sometimes think because we've given up so
much of what the world would count as being things-
that-would-make-you-happy we should be solemn
and we should be sober - well we are sober most of
the time [laughs]. And when they find that we're
different from their perception of what we'd be like,
sometimes it's quite a shock for them and they say-
what makes you so happy? But it's not just today that
we're happy, we were happy yesterday and we'll be
happy again tomorrow: it's a permanent state. And
again it always comes back to the same thing: it's
that business about living in God's presence."

Though always good humoured they were also extremely self-aware and confident of their duty, quite capable of gently but firmly declining involvement in our research if they felt it was not in keeping with their beliefs.

\section{Initial Design Development}

Soon after meeting the nuns, we began to imagine possible designs for them. We did not focus on needs or problems that the nuns might have, but instead on providing resources for new engagements with the world that they might find meaningful and compelling. Initial ideas included, for instance, building new musical instruments to join the organ and guitar they already use to accompany the Divine Office, perhaps with an online presence to augment the (physical) bell they use to signal their activities to the surrounding neighbourhood. We imagined that such ideas might appeal to the nuns, but remained dissatisfied because they neither seemed to reflect the specifically spiritual features of the nuns' religious practice nor our underlying interest in designing for interpretation and appropriation.

A conceptual breakthrough came during an offsite meeting when one of us wondered aloud how the nuns decide what to pray for. We realised that this question cut to the heart of their prayer activity, their role in the community, and the ways they are affected by the outside world. It soon led to playful speculation about media bias in their prayers (c.f. [13]), and we wondered if we could design devices that would allow them to draw on a wider range of information sources as a resource for their prayer.
In our development, we were particularly inspired by two examples of previous work. One was our own design of the Local Barometer [8], which displayed text from classified ads based on locations upwind from the home to give an impression of its sociocultural surroundings. The second inspiration was Listening Post by Mark Hansen and Ben Rubin [9], an installation that uses a grid of text displays, suspended on a wire mesh in a darkened space, to show choreographed movements of text scraped from the web according to emotional themes. This piece illustrates admirably the evocative effects that can be obtained by presenting thematically grouped fragments of text from social networking sites.

Our early design development of the basic concept focused on the forms devices might take and the sources of information that might be used. We produced a number of images in which we overlaid scenes from the monastery with renderings of displays taking the form of large boards, of small devices for the garden or dining room, or inset into furniture (see Figure 2). In addition, we collected examples of text and images from RSS news feeds and a variety of social networking sites. Finally, we gathered the sketches and examples of possible content together to create a workbook for presentation to the nuns.

The reactions to the concept designs and illustrations were very strong. Sister Peter and the Mother Abbess, to whom we presented the workbook, engaged with the basic concept of providing a resource for prayer with sophistication and appreciation, but after an initial period in which they expressed simple amazement at the technologies we proposed to use, they became much more critical of the specific proposals on offer. For example, when we showed them the illustration in Figure 2, featuring a very large notice board in the room where the nuns had their recreation meetings, both Sister Peter and the Mother Abbess were aghast in a good humoured way, noting that this was where visitors like the Bishop sat and that something like this would be far too intrusive. They reacted more positively to the smaller standing devices pictured in locations like the library and the garden, but their comments indicated the strength of feelings around the

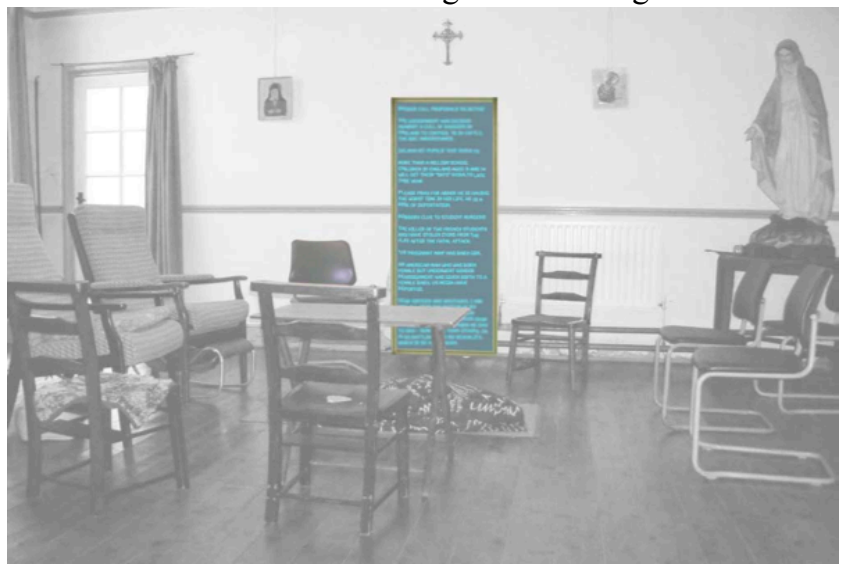

Figure 2: An early sketch proposal. 
appearance and placement of any system we might build.

\section{Refining the Design}

In developing the design of the prototype Prayer Companion, then, we prioritized its material instantiation as much as the software that produced its display content.

\section{Form and Appearance}

From our discussions about the proposal workbook with the nuns, it seemed clear that the device should probably be relatively small to reflect their concerns for obtrusiveness. From that point, most of our design explorations incorporated the particular scrolling text display that we eventually used, though throughout our development we occasionally considered different displays (e.g. LCD displays permitting multiple lines of text to be shown without scrolling) and associated forms. We also considered displaying topical images sourced from the web, but were more interested in continuing previous investigations of the potential for small text displays to present simple messages that can be appreciated from the periphery of attention and which can be specific while retaining a useful degree of openness $[6,8]$.

We pursued the form design through a huge variety of sketches, CAD renderings, paper and cardboard models, and $3 \mathrm{D}$ printed modes using a $\mathrm{Z}$ Corp rapid prototyping machine (see Figure 3). Our form studies reflected our expectations about how the device might be encountered and used. For instance, designs gravitated towards using a horizontally mounted screen both to avoid the distraction that a more widely visible, vertically mounted screen might cause and because we liked the way that a horizontal screen encouraged viewing with a bowed head in a contemplative posture. In a similar way, early experiments with floorstanding displays gave way to table-mounted designs when the nuns told us they thought the device should go on a certain table in their hallway.

Equally importantly, the form studies drew on our research of Roman Catholic relics, conducted in part at the Victoria $\&$ Albert Museum in London. Studying a wide variety of crucifixes, crosses, chalices and candlesticks sensitized us to the aesthetics of such objects, and to an intriguing characteristic shared by many altar-top objects of standing at $35 \mathrm{~cm}$ tall (which incidentally serves as a reasonable ergonomic height to view the horizontal screen of the device when situated on the chosen hallway table). The shape was further informed by the requirements of housing the electronics at the device's base and a screen at the top with the appropriate width for a legible flow of text.

The nuns have likened the final form to the Tao Cross, an ancient $T$ shaped symbol of Christ's cross that is particularly associated with Saint Francis, with which we were familiar. We did not seek to emulate religious artefacts, however, but to create a contemporary piece that would fit harmoniously with, and make reference to, the monastery's existing fittings. The colour, a deep burgundy,

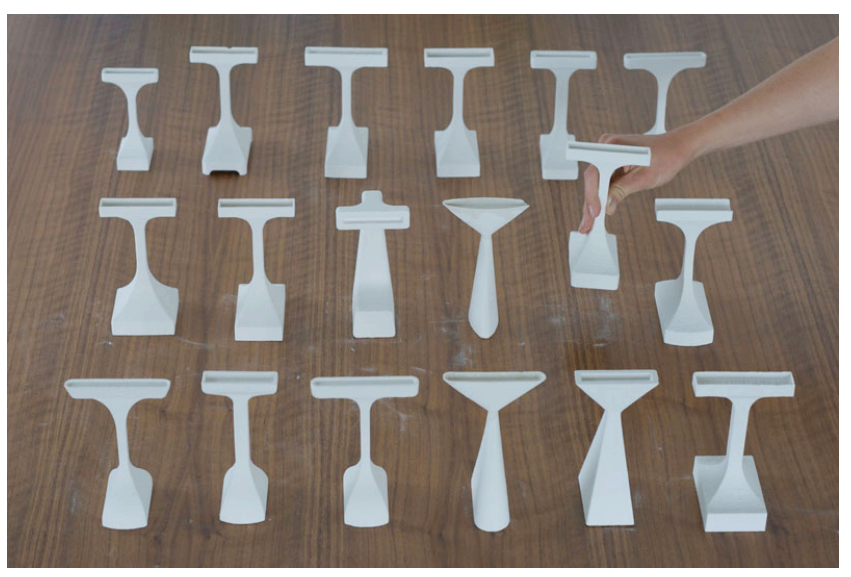

Figure 3: 3D models printed at 1:2.5 scale.

was chosen after much discussion to be sympathetic to the palette of sacred artefacts within their environment.

Once the design was finalized, we produced it using an Objet Eden rapid prototyping machine that allowed us, essentially, to print the case in a durable photopolymer resin from $\mathrm{CAD}$ specifications, making it possible to specify the overall form precisely and moreover to include detailed features such as internal ribbing and mounting points for the electronics. The complete housing was assembled and finished onsite before being taken to an external service to be sprayed. The display device was designed to be tethered to a separate laptop computer that could be hidden nearby; as a final detail the power and data cables were sheathed together in a woven sleeve similar to those used by traditional domestic appliances.

\section{Software and Behaviour}

The Prayer Companion is programmed to show an ongoing stream of headlines from a variety of news sites, mixed with content from wefeelfine.org, a site inspired by the Listening Post [9] that crawls social networking and related sites to collect statements of feeling. The intention in juxtaposing these streams of information was to balance the relatively collective and global issues revealed by news sites with more personal and idiosyncratic content to create representative samples of current worldly concerns that might resource prayer.

Three software modules underlie the Prayer Companion:

- Sourcing. This sources news content and statements of personal feeling (I feels) from the web and automatically uploads it via FTP to a dedicated website.

- Selecting. This makes a varied series of selections from the sourced news and 'I feels' and selects a 'behaviour' by means of which the selected items are to be displayed.

- Displaying. This controls the presentation of scrolling text on the Prayer Companion. The Displaying software runs on an Arduino board embedded in the device.

Below we describe the first two modules in more detail. 


\section{Sourcing}

We chose 25 websites that published content as RSS feeds. Our choice was based on what we knew about the nuns and their interests. Some sites, such as BBC, CNN, Reuters and the New York Times, were chosen to represent the sources they already consult to inform prayer. But we also tried to ensure a broad international coverage with sites from South America, Australasia and Asia, as well as Europe and North America. The point of using multiple, international RSS feeds was to counter media bias associated with any one source by exposing multiple voices. Finally, we also included local news sites as well as sites related to the nuns' interest in gardening. We approximately ordered this list from global (international news sites) to local (local news and special interest sites).

Every five minutes, the Sourcing component chooses 10 sites from the list and retrieves their current RSS content. The software examines the headline field of each RSS item to see if it can serve as an effective digest of the news item and would read well scrolled across the Prayer Companion. Not all headlines are suitable. For example, some only make sense when read in conjunction with the attached story. Others are metaphorical or allude to the story content in some oblique way. We reject headlines longer than 8 words as too taxing to read on the Prayer Companion. To isolate headlines that most effectively serve as news digests we use natural language processing to identify headlines with a subject-verb-object structure. This is the syntax of simple declarative headlines such as 'EU slaps tariffs on US biodiesel' that are readable as complete sentences. All the headlines that satisfy our word length and syntactic criteria are automatically published on a webpage in a global-to-local ordered list. The number of items sourced in each iteration varies between about 20 and 70 depending on which sites are accessed.

In addition to Sourcing news items, we also retrieve content using the published API of wefeelfine.org. The API allows one to identify subsets of statements by criteria such as date or time of day, inferred gender, location, and so on. We initially retrieved 'I feels' which wefeelfine.org inferred were from the city, from England and worldwide to, again, create a list that could be approximately ordered by locality. We applied the same syntactic criterion as before and allowed sentences up to 12 words in length (the everyday English of 'I feels' tends to use shorter words than news headlines). A global-to-local ordered list of feelings was published to another web page. We experimented with the API until the numbers of feelings we were publishing approximately matched the number of news items. The Sourcing component was written in Python using the web and natural language processing libraries that are part of Nodebox (www.nodebox.org).

\section{Selecting}

The laptop tethered to the Prayer Companion retrieves content from the news and feelings webpages and makes selections for display. The Selecting component defines a number of different 'behaviours' that the Prayer Companion can manifest. In 'normal' behaviour a random selection from the combined pool of news items and feelings is made. In a 20-minute cycle, the Prayer Companion will manifest normal behaviour for 19 minutes. In the $20^{\text {th }}$ minute one of a number of 'special' behaviours will be encountered. These include only showing feelings, only local news, showing only one item over and over again, and various manipulations of the speed of display. Normally, one character is shown every $240 \mathrm{~ms}$, an optimal rate for reading scrolling displays. 'Superspeed' behaviour uses a rate of $50 \mathrm{~ms}$ per character and 'superslow' $750 \mathrm{~ms}$. We hoped that varying the Prayer Companion's behaviour on rare occasions would pique interest without disrupting normal reading too much. The Selecting component was implemented using the music and multimedia programming environment $\mathrm{Pd}$ (puredata.info) as this gave us constructs suited to defining and sequencing timed behaviours.

\section{LIVING WITH THE PRAYER COMPANION}

We installed the Prayer Companion in the convent in the Spring of 2009, where it has since been in near-continuous operation. At the nuns' suggestion, the device was situated underneath a noticeboard on a box table under which we hid the tethered computer. This was at the bottom of a major staircase leading down to a central corridor that the nuns walked along regularly throughout the day: when they were going to the refectory, to mass, to say the Divine Office or to the garden. A book for comments was left by the device with a pen selected to match the colour of the device. A simple hand held video recorder was also left for Sister Peter to document discussion of the device, a role she was very happy to take.

\section{Initial Impressions}

Sister Peter and the Mother Abbess were clearly excited and curious to see the device. When it was finally unveiled Sister Peter exclaimed "Oh! That's unobtrusive!" Although this might not seem like the highest praise, one of their main concerns was that it should not be a distraction. During early discussions the Mother Abbess had been particularly insistent that the device should have an off switch. When the device was in situ it became clear that it would be possible to walk past and not read it at all and the aesthetic fitted well with the iconography of the monastery. (It is worth noting that the designers had not previously been invited into enclosure, so the design of the Prayer Companion was informed only by two photographs of the hallway table and its surroundings.) The Tao cross was recognized immediately although the sisters were not sure whether the designers themselves knew of its significance. The initial impressions of the Mother Abbess, Sister Peter and the other nuns who walked by seemed promising, but it was not clear whether it would become a significant part of their lives over time.

Following the deployment of the device the initial reaction in emails was positive yet cautious: 
"Just a very brief word of thanks to start the day. The 'Thing' is still working with no problems so far!!! We did talk quite a bit last night at recreation about it. I suspect the overriding thought was that its a bit early yet to decide just how well or otherwise it will fit in with our life." [Email from Sister Peter]

It is interesting to note here that no commitment to the device is made whatever. This is important because, clearly, when a bespoke design is created for a group of people, there may be a strong tendency to be positive about it solely through a regard for the designers' feelings. But throughout the project the sisters had made it clear that their primary concerns were spiritual and however reluctant they might be to offend the team, total rejection of the device was a real possibility.

\section{'I Feel' Problems: Repetition and Indulgence}

As we will discuss shortly, the sisters engaged positively with the device from the outset and quickly accommodated it to their activities. However, concerns about the 'I feel' statements appeared in the first weeks of the deployment and persisted for some time. The initial problem was that the 'I feels' seemed to be constantly repeating themselves. Sister Peter knew some of them off by heart. Standing by the device she completed "I feel terrifically awesome today" long before the display had finished. Sister Felicity walked by and said she sees "the one about their hair standing on end" all the time. "It's like it's waiting for me, it can see me coming".

Upon checking the log files, we realised that the 'I feels' inferred to be from local sources were updating very rarely, so we adjusted the sourcing component to retrieve feeling without constraint by locality. This corrected the repetition to which the nuns had objected. Even without the repetition, however, the nuns still said that there were too many 'I feels'. For some nuns, the problem seemed to be that they tried to interpret the 'I feels' as literal requests for prayer but found them lacking, while for others the 'I feels' did not provide a useful resource for prayer whatever their original intentions might have been. Sister Matthew asked "Are we supposed to be praying for them? I thought this was supposed to be about prayer." In another conversation, she said that it would be better if the 'I feels' were about a specific problem - "I wish my boyfriend would propose to $m e$ ". That way she might be able to respond in some way with a prayer. Sister Peter gave "I feel thirty-four" as an example "what are you supposed to do with that? You feel thirty-four, OK then". It was irrelevant. Sister Peter complained that she had "wasted a lot of time" waiting for the 'I feels' to pass so that she could get to the news, or something she could use. Mother Abbess said that if she saw any of the "agony aunt" ones she just kept walking.

Despite their insistence that there were too many 'I feels', the nuns did not want to see them disappear altogether. Some seemed to strike them as particularly memorable or moving. Sometimes they were "very sad", Sister Peter remembered "I feel lonely" or "I feel frightened". Sister

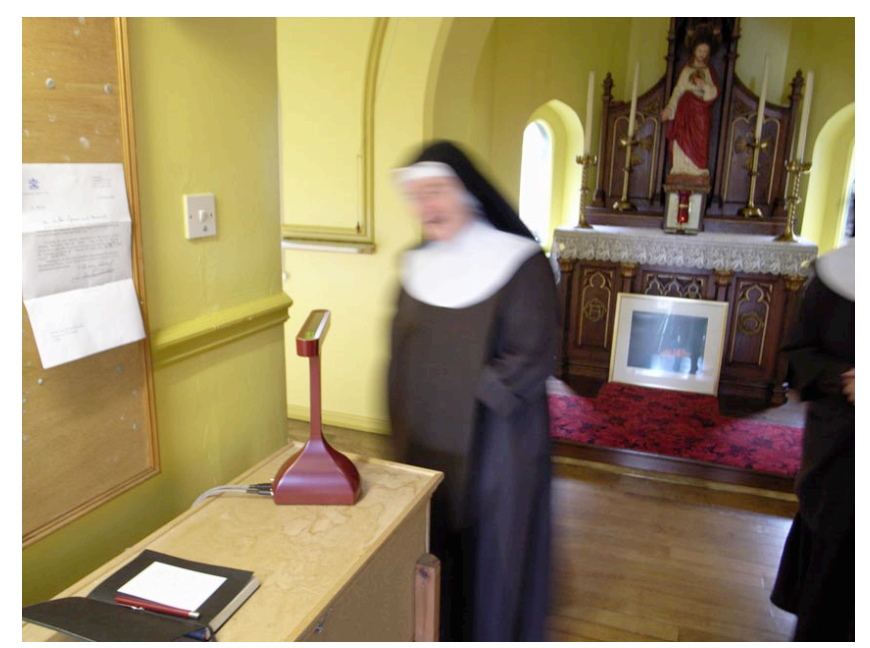

Figure 4: The Prayer Device in the convent.

Peter and Sister Matthew both mentioned times when they had seen positive I feels. "I feel happy. I've got a job and a girlfriend." Similarly in one video clip Sister Matthew talks about seeing an "I feel blessed". "Well" she remarks "that makes a change!". Other times, however, they were " $a$ waste of time for the people who were writing them and certainly a waste of time for us". Many of the 'I feels' seemed trivial and indulgent to the nuns, although when questioned they explained that they did not want to condemn the writers for expressing their feelings so much as to avoid constant reminders of attitudes and difficulties that were already familiar to them.

Although the frequency of 'I feels' was annoying they did provide light relief. It was felt that if only news were shown it might be "a bit too grim". This point was vividly illustrated in one meeting. Sister Matthew was standing over the device and read the words aloud as they appeared.

\section{Device: I feel like I should stop putting myself down. \\ Sister Matthew: [with some sarcasm] Do you? Yes, well very sensible. \\ Device: Fears over missile build up in Iran \\ Sister Matthew: This is what makes us all hold our breath. \\ Device: Southern man beats his wife to death. \\ Sister Matthew: Oh no.}

There were general murmurs of - oh dear, how horrible and so on and the atmosphere was sombre at which point Sister Matthew read the next entry:

\section{Device: I feel pretty, oh so pretty, I feel pretty and witty}

Everyone laughed and the comic relief was palpable.

Even when the device annoyed them they greeted its messages with amused tolerance. The sisters took neither themselves nor the device entirely seriously. Their amusement is not however dismissive. Not taking themselves seriously was a part of their humility but their joy was also an important aspect of their worship. "We are full of joy so why would we not laugh?". The ludic elements 
of the design such as the feeds from gardeners and some of the amusing 'I feel' feeds were sometimes appreciated in this spirit of joyful amusement even when the proportion felt imbalanced.

\section{'I Feel' Changes}

We responded to the nuns' irritation with the 'I feels' in two ways. The first involved changing the system software to reduce the number of 'I feel' statements from about a half to a quarter of the outputs. The nuns were most appreciative. The Mother Abbess declared that it had "made all the difference in the world" and wrote in the comment book "I have been here for about five minutes and not one I feel. What a difference it makes!" The second response involved shaping the sisters' interpretation of the system by suggesting that they think about how 'I feel' statements reveal the underlying attitudes and situations of their writers, rather than interpreting the statements as literal requests for prayer. After our interventions, both the Mother Abbess and Sister Peter said that the 'I feels' were at about the right level. Although they still felt some of the statements were "silly" they were now inclined to think of the person behind the words. Sister Peter explained "Part of our responsibility is to pray for people who can't pray for themselves [...] I realised I think that if these people don't even know how to pray, these are almost their emotional states which often is how you pray ...but maybe these people don't even know how to formulate that into the idea of a prayer so what they're doing is to talk to each other because they don't know to talk to God sometimes." Our discussion about the intent of 'I feel' statements seems to have helped Sister Peter reach such a view.

\section{Accommodating the Prayer Companion}

Despite the initial irritation with the 'I feels', the nuns engaged with the Prayer Companion continuously from the beginning of the deployment and continue to do so at the time of writing. They told us they check it whenever they walk past it, "millions of times a day". Although the device does have an on and off switch as requested it has never been turned off except when the table on which it stood had to be moved to make way for funerals. Mother Abbess described it as beautiful and elegant, Sister Peter emphasised how well it fitted in with the location and how unobtrusive it was.

At the time of deployment we had not decided on a name for the device and invited the nuns to make suggestions. Sister Peter later showed us videos of the recreation periods in which they had discussed this. There is much hilarity as they talk about what the device should be called. Sister Felicity wanted something imaginative, possibly in Latin "to show how educated we are". This was greeted with much laughter. The Mother Abbess suggested calling it 'Goldie' after the architect who designed the monastery and 'Goldsmiths'. One of the other Sisters protested: "oh no that's not very democratic!" and other alternatives were discussed. It was felt that the process shouldn't be rushed, nor left up to the Mother Abbess, who, as Sister Felicity warned, named their dog 'Nobby' in an impetuous moment.

The name 'Goldie' stuck, however, and now the sisters will say "Oh I saw on Goldie ..." and everybody will know exactly what they are referring to. The device is now very much a part of their daily lives. The Mother Abbess noted "we're always talking about it. We just had midday service and Sister Matthew said - the prime minister's going to visit a [local] family and I said-yes I've just seen that [laughs]". Sister Peter agreed but emphasised its role in their prayer:

Sister Peter: Goldie is one, you know with due respect to Goldie and all that you've done, it's one very small part of our whole lives but now it is part of our lives really isn't it [...] And I still do think it has been a help and will continue to be a help to the prayer side of our lives. To me if it weren't doing that I would [...] question why we would need to be bothered about it. It's like -

Mother Abbess: A thought's just come to me, it's like putting salt on your dinner. You know to enhance your dinner.

Sister Peter: And that's it. [...] as we're passing we see it and there's nothing to it, we get on with the rest of our daily lives taking whatever we've seen there with us and carrying it, for, you know, sometimes it's something that we might carry for five minutes, sometimes its something that we'll carry for the whole day. And sometimes if it's an ongoing thing it can carry on for day after day after day. And that for me is one of the beauties about having Goldie about how it's been done, about how they've physically done the design for it because it fits in so, so well.

Indeed they had accommodated the Prayer Companion into their lives to such an extent that Sister Peter said she had stopped trying to videotape discussions of the device because references to it would filter in and out of conversations so quickly that by the time she had grabbed the camera the moment had passed. It was no longer the device itself which was being discussed but the content: "I saw on Goldie that..."

\section{Prayer Life}

Beyond providing a topic of conversation at recreation, the device informs the nuns' prayers.

The Mother Abbess reported that it had had a direct impact on her prayer life almost immediately. On her way to mass she had seen a story about the Pope's visit to Africa. Two people had been killed in a stampede "so we were able to pray for those two souls straight away". Many other examples were described in later meetings. For instance, the device was the first to inform them that a young woman from the local University had gone missing and they followed the story as it developed. Sister Matthew had been out in the garden attending to her snapdragons when she 
noticed helicopters flying overhead. She assumed they must be part of the search for the missing girl because she had read on her way out that they were now treating the case as a murder investigation. Following the Air France crash over the summer they prayed for the victims and families at each stage of the investigation: "I feel that we've prayed all the way through that process from when it first went missing". In many cases, they reported, the device would alert them to an event they would investigate further on the internet or in the news.

One of the things that became clear throughout the project was that their conception of prayer is more complex than simple intercession, thanks or praise. There was a notion of "standing in the presence of God" and this was far more difficult to grasp. For instance, Sister Peter touched on the paradox of prayer: "the problem is [,,,] we know - God already knows these things, so in a sense we don't have to tell him that Michael Jackson's died, a plane has crashed or an earthquake's happened - he already knows." What then was the purpose or power of prayer? "What I feel is, for me it's just saying to God - but it's not even really using words sometimes, it just in your mind, having it there. The old catechism definition of prayer is - the raising of the heart and mind to God. And that's what we do... So what's in our hearts and minds goes into God's presence". It was in the discussion of the uses of the Prayer Companion that this difficult conception of prayer was most clearly articulated. Though they are cut off from the world their prayer is focused on it. Though they are enclosed their faith is inclusive: "A lot of people - either they don't know that God exists. Or they're agnostics. But we're there for all of them. We're here not just for ourselves but for everybody else as well."

The news stories were of immediate value to the nuns because they were of clear relevance to the work of standing in the presence of God for those that could not. The 'I feels', once balanced, also helped in this work. But they were also sometimes funny and contributed to their joyful amusement, also, in a sense, an act of worship.

\section{CONCLUSIONS}

The nuns have been at pains to remind us that they will not come to any conclusions about the value the Prayer Companion has to them for several years. "A month is nothing to us", they explained. In a year, or two years, then they will have an idea. They may yet decide, for instance, that it intrudes upon their seclusion and give it up as a wonderful but inappropriate distraction. During the ten months they have lived with it so far, however, their engagement shows several symptoms of success [6]: they are clearly engaged with the system, compare it with other experiences they value, have accommodated it in their everyday activities, and find that it persistently gives rise to moments of surprise and insight. In this section we discuss the more general lessons the Prayer Companion may hold for the development of computational devices, returning to the four themes with which we started this paper.

\section{Openness Complements Specificity}

The Prayer Companion is a clear example of a device designed for a particular group of users, with functionality, content and appearance all carefully crafted to fit the nuns' environment and activities. At the same time, decisions over content provided by the device, the headlines and 'I feel' statements, were left relatively open. It appears that the design's specificity and openness complement one another. On the one hand, the specificity of the Prayer Companion's appearance and its explicit description as a device for prayer persuaded the nuns to accept it as a valid resource for their convent rather than a worldly distraction. On the other hand, the openness of the content it provides allowed the device to be appropriated by the nuns for use in a prayer activity that we did not completely understand, and even when they disapproved of the 'I feel' statements we thought might be of particular import. In addition, the nuns' reconciliation to the 'I feels' depended as much on changing their interpretation of them as it did on reducing their actual numbers. In short, the specificity of understanding we embodied in the design promoted engagement, while its openness encouraged forgiveness.

Achieving requisite openness in the Prayer Companion involved holding back from the degree of detail that might have appeared possible given our understanding of the nuns and our design intentions. For instance, we chose sources of information we thought would be relevant for prayer, but did not presume to select specific instances as valid. The system does not present its content explicitly as prayerworthy, but leaves space for some statements to be regarded as directly relevant, others as suggestive, and others as irrelevant. Even the form of the Prayer Companion is designed to be sympathetic to Catholic artefacts, but not to literally emulate them or incorporate religious symbols. In sum, we consistently designed the device to be a bit vague about its expected use and interpretation, and this seemed key to its appropriation.

\section{Materiality is Meaning}

The nuns' engagement with the Prayer Companion suggests that engaging deeply with the materiality and aesthetics of prototypes can have a significant impact on their acceptance and interpretation. Beyond any direct functional effect on, for instance, readability or obtrusiveness, the way the Prayer Companion fits with the convent's ambience was a significant source of the specificity that encouraged the nuns to interpret it as a resource for prayer. What this suggests is that we separate the functionality and materiality of our prototypes at our peril. By definition, of course, prototypes do not resolve all issues relevant for a final product. Commonly there is a temptation to focus on technical functionality while sidelining materiality to be dealt with later. Our work suggests this may be problematic, however, because materiality can play a fundamental role in defining the meaning and identity of technological devices. 
Older People are Nuns, and Fishermen, and...

The Prayer Companion's focus on spirituality and on providing easy access to information might well appeal to other older people. It is important to note, however, that we did not build the device for older people in general, but for a specific category of people - nuns - who happen to be old. We believe there is a lesson in this. 'Design for older people', whether focused on disability or development, has the tendency to direct attention to a single dimension of comparison among people who may otherwise have little in common. Developing technologies to have meaning to older people in general may be an intractable problem, however, particularly if one considers that age may be associated with personality differentiation rather than assimilation to a norm [1]. Designing for specific groups of older people, on the other hand, may be a useful way to overcome stereotypes about aging. In sum, the Prayer Companion suggests that, rather than designing for an aging population, we should design for the aging members of many different populations.

\section{Computers Can Support Prayer}

One of our primary motivations for working with the Poor Clare nuns was to investigate whether we could design a computational device that would support spiritual activity relatively directly. We believe the Prayer Companion has gone a long way towards achieving this: as the nuns' comments indicate, they experience the device as playing a significant role in their prayer, welcome it in their enclosure because and insofar as it plays this role, and have made it clear that if it had not been useful in this way they would not value it so highly or, perhaps, at all.

The ability of the Prayer Companion to serve as a resource for the nuns' prayer life is not based on content or functionality alone. Its materiality has also lent it a specificity that accords with the convent, while its openness has allowed the nuns to appropriate it into their particular form of spirituality. Attending to specificity, openness and materiality appears to have been crucial in designing successfully for the nuns' spirituality. Our conclusion is not that these factors are useful in designing for spirituality alone, however. Working with the convent has exposed our existing practice of balancing specificity and openness, and serves as a reminder of the importance of attending carefully to materiality. We believe that these concerns are relevant to any interaction design.

\section{ACKNOWLEDGEMENTS}

This work was carried out in The Landscapes of Cross General Engagement project (RES-352-25-0030), which is part of the UK's Joint Councils 'New Dynamics of Ageing' Research Programme. We are deeply grateful to Sister Peter and the nuns from St. Johns - not their real names - for their participation and inspiration.

\section{REFERENCES}

1. Coleman, R. Designing for Our Future Selves. In Preiser, W. and Ostroff, E. (eds.) Universal Design Handbook. McGraw Hill (2001) 4.1-4.25.

2. Cooper, G and Bowers, J. Representing the user. In The Social and Interactional Dimensions of Human-Computer Interfaces, P. Thomas, Ed. Cambridge Univ. Press, 48-66.

3. Crampton-Smith, G. and Tabor, P. 1996. The role of the artistdesigner. In Bringing Design To Software, T. Winograd, Ed. ACM, New York, NY, 37-61.

4. Dalsgaard, P, Designing for inquisitive use. Proc. DIS'08, 2130.

5. Frayling, C. Research in Art and Design. Royal College of Art Research Papers 1, 1 (1993),1-5.

6. Gaver, W, Bowers, J, Kerridge, T, et al. Anatomy of a failure. Proc. CHI '09, 2213-2222.

7. Gaver, W., Beaver, J., and Benford, S., Ambiguity as a resource for design. Proc. CHI'03 233 - 240.

8. Gaver, W., Boucher, A., Law, A., et al. Threshold devices. Proc. CHI '08. 1429-1438.

9. Hansen, M and Rubin, B. Listening Post: Giving Voice to Online Communication. Proc. ICAD’02, p. 1.

10. Hassenzahl, M., The interplay of beauty, goodness, and usability in interactive products. Human-Computer Interaction, 2004. 19(4): 319-34.

11. McCarthy, J and Wright $\mathrm{P}$. Technology as Experience. Cambridge Mass: MIT Press 2004.

12. Mynatt, E, Rowan, J, Craighill, S, and Jacobs, A. Digital Family portraits. Proc. CHI'01 333-340.

13. Park, S, Kang, S, Chung, S, and Song, J. NewsCube: delivering multiple aspects of news to mitigate media bias. Proc. CHI '09. 443-452.

14. Pousman, Z, Romero, M, Smith, A, and Mateas, M. Living with Tableau Machine. Proc. UbiComp '08, 370-379.

15. Pullen, G., Design meets Disability. MIT Press.

16. Sengers, P. and Gaver, W., Staying open to interpretation. Proc. DIS'06, 99-108.

17. Vetere, F., Davis, H., Gibbs., M., Howard, S., The Magic Box: Responding to the challenge of distributed intergenerational play. IJHCS, 67,2 (2009) 165-178.

18. Wherton, J., and Monk., A. Designing Cognitive Supports for Dementia. SIGACCESS'86. 28-31.

19. Willis, Paul (2000) The Ethnographic Imagination. Polity Press, Cambridge

20. Woodruff, A., Augustin, S., and Foucault, B., Sabbath Day Home Automation: "It's Like Mixing Technology and Religion." Proc. CHI'07. 527-536.

21. Wyche, S and Grinter, R Extraordinary computing: religion as a lens for reconsidering the home. Proc. CHI '09, 749-758.

22. Wyche, S, Caine, K, Davison, B, et al. Sun Dial: Exploring techno-spiritual design through a mobile islamic call to prayer application. Proc CHI'08, 3411-3416.

23. Wyche, S, Hayes, G, Harvel, L, and Grinter, R, Technology in Spiritual Formation. Proc. CSCW'06, 199--208.

24.Zimmerman, J., Research through Design as a Method for Interaction Design Research in HCI. Proc. CHI'06 493-503. 